\title{
The prevalence of overweight and obesity and associated factors among adults in Goni Gora Kaduna State, Northwestern Nigeria
}

\author{
Chinedu J.C. Igboanusi, ${ }^{1}$ Istifanus Anekoson Joshua, ${ }^{2}$ Julius Henry, ${ }^{3}$ Awawu Grace Nmadu, ${ }^{2}$ \\ Mary Ojoneme Onoja-Alexander ${ }^{4}$ \\ ${ }^{1}$ Department of Public Health, Headquarters 2 Division Medical Services \& Hospital, Nigerian Army, \\ Adekunle Fajuyi Cantonment, Ibadan, Nigeria; ${ }^{2}$ Department of Community Medicine, College of Medicine, \\ Kaduna State University, Kaduna, Nigeria; ${ }^{3}$ Department of Pediatrics, Barau Dikko Teaching Hospital, \\ Kaduna, Kaduna State, Nigeria; ${ }^{4}$ Department of Community Medicine, Ahmadu Bello University, Zaria, \\ Nigeria
}

\begin{abstract}
Obesity is an epidemic disease in many developed countries and an emerging public health problem in developing countries, particularly in urban settings. The aim of this study was to determine the prevalence of overweight and obesity and the associated factors among adult residentsin Goni Gora community in Kaduna State. The study was conducted in Goni Gora a semi-urban setting in Chikun Local Government Area of Kaduna State, Northwestern Nigeria in January 2017. A multi-stage sampling technique was used to select 192 adult residents in the community. Data was collected using structured, pretested and interviewer-administered questionnaire using mobile data collection method (Epiinfo ${ }^{\mathrm{TM}}$ version 7.2). Data were analyzed using the Statistical Package for Social Sciences (SPSS) software version 21. The level of significance was set at a $\mathrm{P}$ value of $\leq 0.05$. The majority of the respondents $(32.3 \%)$ were within the age group of 20-29 years. The mean age of respondents was $34.6 \pm 13.1$ years and males $(52.1 \%)$ comprised the majority of the respondents. All the respondents were Christians with $55.2 \%$ of them being married. The prevalences of
\end{abstract}

Correspondence: Chinedu J.C. Igboanusi, Department of Public Health, Headquarters 2 Division Medical Services \& Hospital, Nigerian Army, Adekunle Fajuyi Cantonment, Ibadan, Nigeria

Tel.: +234.803.3432.656

E-mail: chinedujc@yahoo.com

Key words: Prevalence, overweight, obesity, risk factors, Goni Gora, Kaduna.

Contributions: the authors contributed equally.

Conflict of interest: the authors declare no potential conflict of interest.

Funding: none.

Received for publication: 8 August 2018.

Revision received: 26 October 2018.

Accepted for publication: 17 November 2018

This work is licensed under a Creative Commons Attribution NonCommercial 4.0 License (CC BY-NC 4.0).

(C) Copyright C.J.C. Igboanusi et al., 2018

Licensee PAGEPress, Italy

Annals of African Medical Research 2018; 1:40

doi:10.4081/aamr.2018.40 overweight and obesity were $6.7 \%$ and $1.1 \%$ respectively. Age ( $\mathrm{P}=0.001)$, sex $(\mathrm{P}=0.001)$, marital status $(\mathrm{P}=0.002)$, average monthly income $(\mathrm{P}=0.004)$ and duration of physical activities per day $(\mathrm{P}=0.001)$ were found to be associated with overweight and obesity. There was, however, no association found between obesity and educational status $(\mathrm{P}=0.195)$. Overweight and obesity were found to be prevalent among the respondents in the study. Factors such as age, gender, marital status, average monthly income and duration of physical activities per day were found to be associated with overweight and obesity. There is a need to mount intervention programs that are targeted at prevention and control of overweight and obesity in the community.

\section{Introduction}

Obesity is an epidemic public health problem in many countries around the world. It is an epidemic disease in many developed countries and an emerging public health disease in developing countries, and more noticeably urban settings. ${ }^{1,2}$ Overweight and obesity are medical conditions characterized by the accumulation of excess body fat that may impair health. ${ }^{1}$ Obese patients are at higher risk of early death, mainly from its complications such as diabetes, coronary heart disease and cerebrovascular disease. Other complications include non-alcoholic steatohepatitis, osteoarthritis, polycystic ovarian syndrome, cancers, psychological morbidity and socioeconomic disadvantage among others. ${ }^{1,3}$ The morbidity and mortality rates due to obesity increase as obesity become more severe, however, weight reduction reduces both. Men who are $10 \%$ overweight have $13 \%$ increased risk of death, while the increase in mortality for those that are $20 \%$ overweight is $25 \% .^{4}$ Genetics is strongly linked to the etiology of obesity whose pattern of inheritance suggests a polygenic disorder. ${ }^{4}$ Many factors related to an individual's environment, such as increased finance, consumption of energy-dense foods, car ownership, use of automated appliances, sedentary lifestyle all contribute to decreasing energy expenditure and hence obesity. Other etiological factors include hypothyroidism, Cushing's syndrome and some drugs ${ }^{3}$

Body Mass Index (BMI) is an important tool in quantifying the severity of obesity in adults; and it is weight in kilograms divided by the height in meter squared. Obesity in terms of BMI is defined as a BMI greater or equal to $30.0 \mathrm{Kg} / \mathrm{m}^{2}$ and overweight is BMI between $25.0-29.9 \mathrm{Kg} / \mathrm{m}^{2}$. For optimal health, the BMI should be between $18.5-24.9 \mathrm{Kg} / \mathrm{m}^{2}$ while any BMI below $18.5 \mathrm{Kg} / \mathrm{m}^{2}$ is underweight. ${ }^{1,3}$

In 1997 the World Health Organization (WHO) formally recognized obesity as a global epidemic. ${ }^{5}$ Globally about 2.8 million people die each year as a result of being overweight or obese. ${ }^{1}$ It 
has been projected that by 2030 , there will be 2.16 billion overweight individuals among whom 1.12 billion will be obese. ${ }^{6}$ Obesity does not only affect adults but children also. In 2014, it was estimated that 1.9 billion adults aged 18 years and above were overweight or obese, of whom over 600 million were obese which is about $13 \%$ of the world's adult population $(11 \%$ of men and $15 \%$ percent of women) were obese. ${ }^{1}$

The prevalence of adult and childhood overweight and obesity has dramatically increased in recent years in the Sub-Saharan region. ${ }^{7}$ Despite the fact that obesity and overweight is a problem of high-income countries, Low and Medium Income Countries, particularly in urban settings and Sub-Saharan African countries, face the challenge of an increasing trend. ${ }^{1}$ Eritrea, Ethiopia, Democratic Republic of the Congo, and Central African Republic had the lowest prevalence, while Seychelles, Lesotho, South Africa, and Mauritius had the highest prevalence of overweight and obesity in Sub-Saharan Africa. Countries with lower prevalence of overweight and obesity tend to be those with low gross domestic product per capita and vice versa, suggesting that socioeconomic status may be a determinant of overweight and obesity in some African countries. ${ }^{7,8}$ The prevalence of obesity in urban West Africa more than doubled (increased 114\%) from 1995 to 2005. ${ }^{9}$

In Nigeria, adult obesity has been reported to have reached an epidemic level constituting a major health threat. ${ }^{10,11}$ Despite the disadvantageous nature of overweight and obesity, in most cultures in the developing countries, obesity is seen as a symbol of riches and well-being especially Nigeria. ${ }^{12,13}$ The prevalence of obesity varies from one locality to the other in Nigeria. The prevalence of obesity and overweight was found to be $12 \%$ and $47 \%$ respectively in Sokoto State, ${ }^{11} 9.1 \%$ and $26.2 \%$ in Benue, ${ }^{14} 6 \%$ and $38.3 \%$ in Ota Nigeria. ${ }^{15}$ In Kaduna State, the obesity rate was found to be $13.1 \%$ while overweight was $18.5 \% .{ }^{9}$ There is a paucity of data on the prevalence of obesity and overweight available in Goni Gora community, Kaduna State. Hence, this study was carried out to determine the prevalence of overweight and obesity and the associated factors among adults in Goni Gora community Kaduna State.

\section{Materials and Methods}

Goni Gora is a semi-urban setting in Chikun Local Government Area of Kaduna State. It is located along kilometer two Kaduna-Abuja expressway on either side of the road spanning about one kilometre along the road. It is located on latitude $10.26^{\circ}$ and longitude $7.23^{\circ} .{ }^{16}$ The predominant religion in Goni Gora community is Christianity. The original settlers are the Gbagyi people, however, with development the community is now a multiethnic community with tribes from different parts of the country hence the mixture of cultures and beliefs. The common day to day spoken language in the community is English and Hausa. A reasonable number of the occupants work with the civil service, while others involve in businesses and farming.

\section{Study design}

The cross-sectional descriptive study was carried out in Goni, Gora community, Kaduna, Northwestern Nigeria in January, 2017.

\section{Study population}

The study population comprised of all adults living in Goni Gora community in Chikun Local Government Area of Kaduna
State. All residents 18 years and above living in Goni Gora were included in the study. Those who were severely and chronically sick and/or pregnant during the study were excluded.

\section{Sample size estimation}

The sample size (n) for the study population was calculated using Fisher's formula: ${ }^{17}$

$$
\mathrm{n}=\frac{\mathrm{z}^{2} \mathrm{pq}}{\mathrm{d}^{2}}
$$

where $\mathrm{n}=$ minimum sample size

$\mathrm{z}=$ normal standard deviation corresponding to $95 \%$ confidence interval (1.96)

$\mathrm{p}=$ prevalence or proportion of adults who were overweight and obesity from a previous study is $0.131(13.1 \%) .{ }^{9}$

$\mathrm{q}=$ proportion of adult population not overweight or obese (1-P) $=1-0.131=0.869$

$\mathrm{d}=$ error tolerance/ the desired margin of error is $5 \%(0.05)$

Sample size came to 174.88 . By assuming a non-response rate of $10 \%$, a sample of 192 eligible participants was included in the study.

\section{Sampling technique}

A multi-stage sampling technique was used to select the respondents for the study.

Stage 1 (selection of wards): Out of the five wards in Goni Gora, three wards (Ungwan Bije, Ungwan Karatudu and Ungwan Buwaiya) were randomly selected by balloting.

Stage 2 (selection of houses): The houses in each of the randomly selected ward were numbered. Houses with even numbers were selected for the study.

Stage 3 (selection of respondents): In each of the selected houses, all the eligible respondents were numbered out of which one respondent was randomly selected by balloting for the study until the sample size was completed.

\section{Study instruments}

A structured, pretested and interviewer-administered questionnaire using mobile data collection method (Epiinfo ${ }^{\mathrm{TM}}$ version 7.2) was used for data collection. The questionnaire had 3 sections: a) socio-demographic information of the respondents; b) information for BMI calculation and c) information on factors affecting overweight and obesity.

\section{Data collection}

The data were collected with two trained research assistants knowledgeable in English and Hausa. They were trained on the objective of the study, how to fill the questionnaires appropriately without influencing respondents' answer and how to take the weight and height of the respondents appropriately using weighing scale and meter rule. Data collection lasted for about 6 days. The research assistants were supervised daily and their administered tools were checked for accuracy and completeness. Measurements of the weights were taken in Kilogram $(\mathrm{Kg})$ and the measuring scale was standardized each day. The heights were measured in meters. The calculated BMI was used to calculate the prevalence of overweight and obesity in the study population. 


\section{Data analysis}

Data was cross-checked for errors, edited appropriately, entered and analyzed using the Statistical Package for Social Sciences (SPSS) software version 21. BMI categories were defined using WHO cut-offs calculated as body weight $(\mathrm{kg})$ divided by the height squared $\left(\mathrm{m}^{2}\right)$. For all categorical variables, mean and standard deviations were determined. Data were presented in frequency and proportions. Chi-Square tests were applied for comparison of proportions and for evaluating associations of categorical variables. Fisher's exact test was used where applicable. Statistical significance was taken as P-values equal to, or less than 0.05 .

\section{Ethical considerations}

Institutional ethical clearance was obtained from the Health Research Ethics Committee of Ahmadu Bello University Teaching Hospital, Zaria, Nigeria. Permission to carry out the study in the community was obtained from the community head. Participation in the study was voluntary and confidentiality was ensured, and informed consent was also obtained from the participants before data collection.

\section{Results}

A total of 192 questionnaires were administered to the respondents using mobile data collection method (Epiinfo ${ }^{\mathrm{TM}}$ version 7.2). The response rate was $100 \%$. Majority of the respondents (32.3\%) were within the age group of 20-29 years. The mean age was $34.6 \pm 13.1$ years. Males comprised the majority of the respondents (52.1\%). All the respondents were Christians with $55.2 \%$ of them married and $41.1 \%$ single. The Gbagyi tribe made up $17.2 \%$ of the respondents while people from other ethnic backgrounds (Jaba, Yoruba, Igbo, Hausa, Idoma, Adara, Atakar, Atiap, Baju, Eggon, Igala, Igueben, Ikulu, Inuma, Jugun, Kagoro, Kanuri, Kataf, Koro, Kulere, Kuturmi, Mada, Margi, Marwa, Ninzon, Tiv, Edo, and Effik) formed the majority of the respondents (68.2\%). About $7.8 \%$ of the respondents had primary education, $50.5 \%$ had secondary and $41.7 \%$ had tertiary education (Table 1 ).

About $29.2 \%$ of the respondents were overweight, $19.3 \%$ were
Table 1. Socio-demographic characteristics of respondents inGoni Gora community (n=192).

\begin{tabular}{lcc}
\hline Characteristics & Frequency & Percent \\
Age (in years) & & \\
$<20$ & 24 & 12.5 \\
$20-29$ & 62 & 32.3 \\
$30-39$ & 32 & 16.7 \\
$40-49$ & 39 & 20.3 \\
$50-59$ & 29 & 15.1 \\
$60-69$ & 4 & 2.1 \\
$>70$ & 2 & 1.0 \\
Sex & & \\
Male & 100 & 52.1 \\
Female & 92 & 47.9 \\
\hline Marital status & & \\
Single & 79 & 41.1 \\
Married & 106 & 55.2 \\
Widow & 2 & 1.0 \\
Widower & 5 & 2.6 \\
Tribe & & \\
Gbagyi & 33 & 17.2 \\
Idoma & 15 & 7.8 \\
Yoruba & 13 & 6.8 \\
Others & 131 & 68.2 \\
\hline Educational level & & \\
Primary & 15 & 7.8 \\
Secondary & 97 & 50.5 \\
Tertiary & 80 & 41.7 \\
\hline
\end{tabular}

Table 2. BMI of respondents according to WHO BMI cut off values $(n=192)$.

\begin{tabular}{lcc}
\hline BMI $\left(\mathrm{Kg} / \mathrm{m}^{2}\right)$ & Prequency & Percent \\
$<18.5$ [underweight] & 9 & 4.7 \\
18.5-24.9 [normal weight] & 90 & 46.9 \\
\hline $25.0-29.9$ [overweight] & 56 & 29.2 \\
$30.0-34.9$ [class I obesity] & 25 & 13.0 \\
\hline $35.0-39.9$ [class II obesity] & 4 & 2.1 \\
* $^{*} 40.0$ [class III obesity] & 8 & 4.2 \\
\hline
\end{tabular}

Table 3. Association of BMI with Socio-demographic Characteristics of respondents ( $n=192)$.

\begin{tabular}{|c|c|c|c|c|c|c|}
\hline \multirow[t]{2}{*}{ Characteristics } & \multicolumn{4}{|c|}{ BMI $\left(\mathrm{Kg} / \mathrm{m}^{2}\right)$} & \multirow[t]{2}{*}{ Test } & \multirow[t]{2}{*}{ P value } \\
\hline & $<18.5$ & $18.5-24.9$ & $25.0-29.9$ & $>30.0$ & & \\
\hline \multicolumn{7}{|l|}{ Age (years) } \\
\hline$<20$ & 4 & 16 & 4 & - & $\mathrm{FET}=57.536$ & 0.000 \\
\hline $20-29$ & 3 & 40 & 13 & 6 & & \\
\hline $30-39$ & 1 & 14 & 12 & 5 & & \\
\hline $40-49$ & - & 6 & 16 & 17 & & \\
\hline $50-59$ & 1 & 8 & 11 & 9 & & \\
\hline $60-69$ & - & 4 & - & - & & \\
\hline$>70$ & - & 2 & - & - & & \\
\hline \multicolumn{7}{|l|}{ Sex } \\
\hline Male & 5 & 58 & 28 & 9 & $\mathrm{FET}=17.326$ & 0.000 \\
\hline Female & 4 & 32 & 28 & 28 & & \\
\hline \multicolumn{7}{|l|}{ Marital status } \\
\hline Single & 5 & 49 & 17 & 8 & $\mathrm{FET}=22.018$ & 0.002 \\
\hline Married & 4 & 37 & 39 & 26 & & \\
\hline Widow & - & 1 & - & 1 & & \\
\hline Widower & - & 3 & 0 & 2 & & \\
\hline \multicolumn{7}{|l|}{ Educational level } \\
\hline Primary & - & 10 & 2 & 3 & $\mathrm{FET}=8.225$ & 0.195 \\
\hline Secondary & 7 & 48 & 28 & 14 & & \\
\hline Tertiary & 2 & 32 & 26 & 20 & & \\
\hline
\end{tabular}


obese and 4.7\% were underweight (Table 2).

There was statistically significant relationships between age of respondents' $(\mathrm{FET}=57.536, \mathrm{P}$-value $=0.000)$, gender $(\mathrm{FET}=17.326$, $\mathrm{P}$-value $=0.000)$, marital status $(\mathrm{FET}=22.018, \mathrm{P}$-value $=0.002)$ and BMI. There was however, no significant relationship between respondents' educational level and BMI (FET $=8.225$, Pvalue $=0.195)$ (Table 3).

There was a statistically significant relationship between respondents' average monthly income and BMI (FET=15.697, Pvalue $=0.0 .004)$ (Table 4).

There was a statistically significant relationship between respondents' duration of physical exercise per day and BMI (FET $=28.031$, P-value $=0.001$ ) but there was no statistically significant relationship between engagement in physical activities and BMI (FET=4.262, $\mathrm{P}$-value=0.225) (Table 5).

\section{Discussion}

The study was carried out in Goni Gora community, a semiurban setting in Chikun Local Government Area of Kaduna State. The prevalence of overweight and obesity from the study were found to be $29.2 \%$ and $19.3 \%$ respectively. This was higher compared to what was reported in a study done in 2007 in suburban northern Nigeria where the prevalence of overweight and obesity were $18.5 \%$ and $13.1 \%$ respectively. ${ }^{9}$ However, the higher prevalence of overweight and obesity observed in the current study can be explained as a result of the trend of the global increase in overweight and obesity over time. ${ }^{18}$ In another study in Sokoto State, ${ }^{11}$ the prevalence of overweight was $47.0 \%$ which was much higher than what was found in the current the study but that of obesity was much lower $12.5 \%$ compared to the prevalence of $19.3 \%$ in this study. The prevalence of obesity, however, was found to be $9.1 \%$ while the prevalence of overweight was found to $26.2 \%$ in Benue State. ${ }^{14}$ The differences in the prevalence of obesity observed in the different stated in the north may be due to factors such as ethnic differences and differences in culture and customs as well as dif- ferences in the types of diet consumed among other factors.

The prevalence of overweight and obesity has been reported to be higher in the developed countries in contrast to developing countries. ${ }^{19}$ The prevalence of overweight and obesity were highest in the WHO Regions of the Americas with $62 \%$ for overweight in both sexes, and $26 \%$ for obesity, ${ }^{19}$ while in England, $58 \%$ of women and $65 \%$ of men were overweight or obese. ${ }^{20}$ It is, however, lowest in the WHO Region for Southeast Asia with 14\% overweight in both sexes and 3\% for obesity. ${ }^{19}$ In all WHO Regions, women were more likely to be obese than men. In the WHO Regions for America and Europe, over $50 \%$ of women were overweight with roughly half of the overweight women in these regions being obese. ${ }^{19}$ This agrees with the finding in this current study where the majority of the obese respondents $(75.7 \%)$ were females.

The current study identified several factors that were associated with obesity which have also been documented in previous studies. In this study age was found to have a statistically significant relationship with BMI (P-value=0.000). Overweight and obesity were both found to increase from the age range of 20-29 years to its peak at 40-49 years and then declined from the age range of 50-59 years. This observed initial increase could be explained by the fact that body fat increases with age. ${ }^{3,4}$ This finding is in agreement with a review done on the epidemic of obesity that confirmed that obesity is usually at peaks by 50 years of age before declining in developing countries. In relation to gender, the current study showed that being female was found to have a statistically significant relationship with BMI $(\mathrm{P}$-value $=0.000)$. This was in consonance with a WHO report that women were more likely to be obese than men. ${ }^{19}$ The high prevalence of obesity in women could be as a result of their physiologic characteristic of more fat deposit than men. ${ }^{4}$ Being married and postpartum weight gain that is not shed off with increasing parity could also contribute to the higher prevalence of obesity and overweight in women. ${ }^{21}$ Majority of the overweight and obese respondents in the current study were married. This was similar to findings in other studies that confirmed that being married was associated with high BMI. ${ }^{22-24}$ This observation

Table 4. Association of BMI with Average monthly income (n=192).

\begin{tabular}{|c|c|c|c|c|c|c|}
\hline \multirow{2}{*}{\multicolumn{2}{|c|}{ Average monthly income }} & \multicolumn{2}{|c|}{ BMI $\left(\mathrm{Kg} / \mathrm{m}^{2}\right)$} & \multirow{2}{*}{$25.0-29.9$} & Test & \multirow[t]{2}{*}{ P value } \\
\hline & & $<18.5$ & $18.5-24.9$ & & $>30.0$ & \\
\hline$<74999$ & 9 & 89 & 49 & 30 & $\mathrm{FET}=15.697$ & 0.004 \\
\hline $75000-100000$ & - & - & 5 & 5 & & \\
\hline$>100000$ & - & 1 & 2 & 2 & & \\
\hline Total & 9 & 90 & 56 & 37 & & \\
\hline
\end{tabular}

Table 5. Association of BMI with physical exercise and duration of exercise per day (n=192).

\begin{tabular}{|c|c|c|c|c|c|c|}
\hline Characteristics & $<18.5$ & $18.5-24.9$ & $\begin{array}{l}\text { VII }\left(\mathrm{Kg} / \mathrm{m}^{2}\right) \\
25.0-29.9\end{array}$ & $>30.0$ & & Test P value \\
\hline $\begin{array}{l}\text { Physical exercise } \\
\text { Yes } \\
\text { No }\end{array}$ & $\begin{array}{l}7 \\
2\end{array}$ & $\begin{array}{l}48 \\
42\end{array}$ & $\begin{array}{l}24 \\
32\end{array}$ & $\begin{array}{l}20 \\
17\end{array}$ & $\mathrm{FET}=4.262$ & 0.225 \\
\hline $\begin{array}{l}\text { Duration of exercise per day } \\
<30 \text { minutes } \\
1 \text { hour } \\
1 \text { hour } 30 \text { minutes } \\
2 \text { hours } \\
>2 \text { hours }\end{array}$ & $\begin{array}{l}4 \\
- \\
3 \\
- \\
-\end{array}$ & $\begin{array}{l}12 \\
11 \\
16 \\
7 \\
2\end{array}$ & $\begin{array}{l}15 \\
5 \\
4 \\
- \\
-\end{array}$ & $\begin{array}{l}14 \\
6 \\
- \\
- \\
-\end{array}$ & $\mathrm{FET}=28.031$ & 0.001 \\
\hline
\end{tabular}


has been explained by the possibility of being multiparous when married or weight gain may arise as couples; especially women are obliged to regularly consume "richer" and energy-dense foods and abandon the desire to attract a mate when married.22 Another explanation given is as a result of spousal influence, when a partner is willing to yield to their partner's request to either loose or gain weight as in this case. ${ }^{25,26}$

The current study in contrast to other studies ${ }^{27-29}$ found a negative association between income and BMI. Majority of the people in the low-income group were overweight or obese. Studies carried out in Kenya, ${ }^{30}$ Ghana $^{31}$ and even Nigeria ${ }^{32}$ reported obesity to be more prevalent among adults of high economic status than those of low economic status. However, it has also been reported that individuals belonging to low-income households also gain weight because they tend to be food-insecure and are therefore, likely to consume high-energy staples and cheaper parts of meats because they are less expensive. ${ }^{33,34}$

The current study found no statistical significant association between educational status and BMI (P-value=0.195). From some studies overweight and obesity seemed to be higher among noneducated adults, ${ }^{23}$ and less-educated than educated adults. ${ }^{35,36} \mathrm{On}$ the contrary, other studies have found overweight and obesity to be higher among adults with higher education, although this observation was found to be mainly influenced by age and income status. ${ }^{31}$ Similarly, in the current study affirming to engage in physical activities was not found to be associated with BMI (Pvalue $=0.225$ ). However, duration of physical exercise per day was found to be statistically associated with BMI (P-value=0.001). The WHO has recommended at least 30 minutes of physical activities per day for at least 3 days in a week. ${ }^{20}$ It has been reported that changing food consumption with decreasing physical activity levels at work and leisure are direct determinants of excess weight. ${ }^{37}$ It is also reported that normal weighting adults are likely to transit into overweight within 2 years of inadequate physical activity. ${ }^{38}$

Goni Gora being an semi-urban settlement may have had an influence on the high prevalence of overweight and obesity in the community. This is because the urban environment has been implicated in compounding the problem of overweight and obesity. In African populations, $20-50 \%$ of overweight and obese adults have been found to live in urban areas. ${ }^{39,40}$ Overweight and obesity more than doubled within 15 years among urban women in West Africa. ${ }^{2}$ In a Ghanian study, it was found that the overweight population in Ghana were more likely to reside in the southern sector and in urban areas than in rural areas. ${ }^{41}$ Although, some studies have demonstrated overweight and obesity to be higher among rural than urban adults. ${ }^{42,43}$

\section{Conclusions}

The prevalence of overweight and obesity were $6.7 \%$ and $1.1 \%$ respectively among the study population, and several factors such as age, gender, marital status, average monthly income and duration of physical activities per day were found to be associated with overweight and obesity. Based on the finding of the study the following recommendations were made:

There should be continuous health education of the general populace on the causes, health consequences, treatment and prevention of overweight and obesity at community, state and federal levels. The provision of sporting activities in the communities is also very important. The Department of Health Chikun Local Government Area, Kaduna State Ministry of Health, Federal Ministry of Health, faith based organizations, non-governmental organizations, Ministry of sports among others. The Health personnel in the community should also organize periodic community outreach where the people should be educated on the need of adopting healthy lifestyles such as physical exercise and good dieting.

Lack of data on the occupation of the respondents was a weakness of the study because there is relationship between occupation and the chances of developing overweight and obesity.

\section{References}

1. WHO. Obesity and Overweight Fact Sheet 2016 [updated June 2016; cited 20167 September]. Available from: www.who.int/mediacenter/factsheets/fs311/en/.

2. Abubakari A, Lauder W, Agyemang C, et al. Prevalence and time trends in obesity among adult West African populations: a meta-analysis. Obes Res 2008;9:297-311.

3. Hanlon P, Byer M, Walker B, Macdonald HM. Environmental and Nutritional Factors in Disease. Davidson's Principles and Practice of Medicine. 22 ed. Edinburgh: Churchill Livingstone Elsevier; 2014. p. 115-20.

4. Elia M. Nutrition. Kumar and Clark's Clinical Medicine. 7 ed. Edinburg: Elsevier Saunders; 2009. p. 228-33.

5. Cabellero B. The global epidemic of obesity: an overview. Epidemiol Rev 2007; 29:1-5.

6. Kelly T, Yang W, Reynolds K, et al. Global burden of obesity in 2005 and projections to 2030. Int J Obes 2008;32:1431-7.

7. Muthuri S, Francis C, Wachira L, et al. Evidence of an overweight/obesity transition among school-aged children and youth in Sub-Sahara Africa: a systemic review. PLoS ONE 2014;9.

8. Sally N, Walter C, Donna S, Clement AA. Obesity epidemic has emerged among Nigerians. BMC Public Health 2014;14: 455.

9. Mbanya J, Ramiaya K. Disease and Mortality in sub-Saharan Africa: 2nd Edition. The World Bank 2006, Washington, DC.

10. Kolawole W, Wahab M, Sani U, et al. Prevalence and determinants of obesity- a cross sectional study of an adult Northern Nigerian population. Int Arch Med 2011;4.

11. Nkwoka I, Egua M, Abdullahi M, et al. Overweight and obesity among staff of Usman Danfofiyo University, Sokoto, Nigeria. Int Res J 2014;5:290-5.

12. Venter F, Walsh C, Slabber M, Bester CJ. Body size perception of African women (25-44 years) in Mangaung. J. Family Ecol. Cons. Sci. 2009;37:12-23.

13. Prinsloo E, Joubert G, Mohale M, et al. The prevalence and perception of obesity and its association with the lifestyle of women at the Mangaung University Community Partnership Project healthcare centre, Bloemfontein. S Afr Fam Pract 2011;53:366-72.

14. Utoo P, Okpara IC. Prevalence of obesity amongst staff and students of a tertiary institution in Nigeria. IOSR J Dent Med Sci $2013 ; 10: 24-8$

15. Shalom N, Opeyemi CE. Underweight, overweight, and obesity amongst Young adults in Ota, Nigeria. Acad J 2014;6:2358.

16. Goni Gora Map. Nigeria Google Satellite Maps. Available form: http://www.maplandia.com/nigeria/kaduna/chikun/gonigora/accessed January, 2017

17. Singha P. Introduction Text on Biostatistics. third ed. KadunaNigeria: Abdulahi Bello Dabco Investments Limited, 37/39 Yahaya Road; 2002.

18. World Health Organization: Obesity and Overweight Fact 
Sheet. Geneva: 2006.

19. World Health Organization: Obesity Situation and Trends. Geneva: 2016.

20. Health and Social Care Information Center. Statistics on Obesity, Physical Activity and Diet. England: 2016.

21. Onyango O. Post-partum weight change patterns in WHO Multicenter Growth Reference Study. Matern Child Health J 2011;7:228-40.

22. Averett S, Sikora A, Argys LM. For better or worse: relationship status and body mass index. Econ Hum Biol 2008;6:33049.

23. Tzotzas T, Vlahavas G, Papadopoulou S, et al. Marital status and educational level associated to obesity in Greek adults: data from the National Epidemiological Survey. BMC Public Health 2010;10.

24. Simkhada P, Poobalan A, Simkhada P, et al. Knowledge, attitude, and prevalence of overweight and obesity among civil servants in Nepal. Asia-Pac J Public Health 2017;23:507-17.

25. Duda R, Darko R, Seffah J, et al. Prevalence of obesity in women of Accra, Ghana. Afr J Health Sci 2007;14:154-9.

26. Meltzer A, McNulty J, Novak S, et al. Marriages are more satisfying when wives are thinner than their husbands. Soc Psychol Personal Sci 2011;2:416-24.

27. Romling C, Qaim M. Direct and indirect determinants of obesity: the case of Indonesia. Conference paper: Proceedings of the German Development Economics Conference; Berlin; 2011.

28. Olatunbosun S, Kaufman J, Bella AF. Prevalence of obesity and overweight in urban adult Nigerians. Obesity Rev 2011;12:233-41.

29. Subramanian S, Perkins J, Ozaltin E, Smith G. Weight of nations: a socioeconomic analysis of women in low- to middleincome countries. Am J Clin Nutr 2011;93:413-21.

30. Steyn N, Ne J, Parker W, et al. Dietary, social, and environmental determinants of obesity in Kenyan women. Scand J Public Health 2011;39:88-97.

31. Abdulai A. Socioeconomic characteristics and overweight problems in underdeveloped economies: does income really matter? Appl Econ 2010;42:157-69.

32. Uthman OA. Patterns, distribution, and determinants of underand overnutrition among women in Nigeria: a population- based analysis. J Public Health 2009;17:289-99.

33. Hanson K, Soba LJ, Frongillo EA. Gender and marital status clarify associations between food insecurity and body weight. J Nutr 2007;137:1460-5.

34. Rolls B. The relationship between dietary energy density and energy intake. Physiol Behav 2009;97:609-15.

35. Marques-Vidal P, Bovet P, Paccaud F, Chiolero A. Changes of overweight and obesity in the adult Swiss population according to educational level, from 1992 to 2007. BMC Public Health 2010;10:87.

36. Xiao Y, Zhao N, Wan H, et al. Association between socioeconomic status and obesity in a Chinese adult population. BMC Public Health 2013;13:355-65.

37. Romling C, Qaim M. Direct and indirect determinants of obesity: the case of Indonesia. Conference paper: Proceedings of the German Development Economics Conference; Berlin; 2011.

38. Hillemeier M, Weisman C, Chaung C, et al. Transition to overweight or obesity among women of reproductive age. J Women Health 2011;20:703-10.

39. Sodjinou R, Agueh V, Fayomi B, Delisle H. Obesity and cardio-metabolic risk factors in urban adults in Benin: relationship with socio-economic status, urbanization, and lifestyle patterns. BMC Public Health 2008;8:1-13.

40. Kamadjeu R, Edwards R, Atanga J, et al. Anthropometry measures and prevalence of obesity in the urban adult population of Cameroon: an update from the Cameroon Burden of Diabetes Baseline Survey. BMC Publ Health 2006;6:1-8.

41. Dake F, Tawiah E, Badasu DM. Socio-demographic correlates of obesity among Ghanaian women. Publ Health Nutr 2010;14:1285-91.

42. Ayesu EY. Prevalence, perception and socio-demographic determinants of overweight and obesity among Ghanaian women: University of Ghana; 2013.

43. Cleland V, Hume C, Crawford D, et al. Urban-rural comparison of weight status among women and children living in socioeconomically disadvantaged neighbourhoods. Med J Austral 2010;192:137-40. 